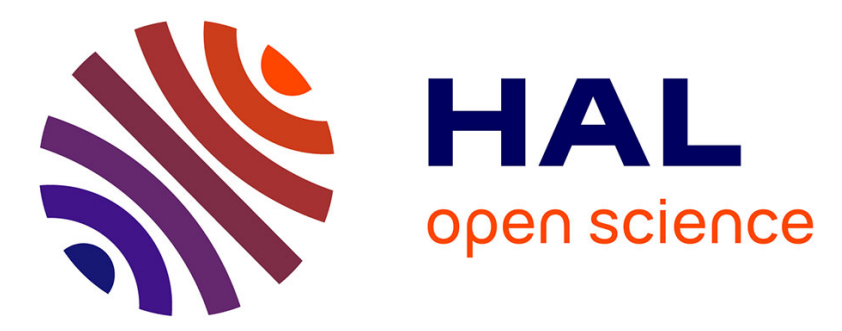

\title{
Ajustements technico-économiques possibles de l'alimentation des volailles dans les pays chauds
}

\author{
M. Picard, B. Sauveur, F. Fenardji, I. Angulo, P. Mongin
}

\section{To cite this version:}

M. Picard, B. Sauveur, F. Fenardji, I. Angulo, P. Mongin. Ajustements technico-économiques possibles de l'alimentation des volailles dans les pays chauds. Productions Animales, 1993, 6 (2), pp.87-103. hal-00896046

\section{HAL Id: hal-00896046 \\ https://hal.science/hal-00896046}

Submitted on 1 Jan 1993

HAL is a multi-disciplinary open access archive for the deposit and dissemination of scientific research documents, whether they are published or not. The documents may come from teaching and research institutions in France or abroad, or from public or private research centers.
L'archive ouverte pluridisciplinaire HAL, est destinée au dépôt et à la diffusion de documents scientifiques de niveau recherche, publiés ou non, émanant des établissements d'enseignement et de recherche français ou étrangers, des laboratoires publics ou privés. 
INRA Prod. Anim., $1993,6(2), 87-103$.
M. PICARD, B. SAUVEUR, F. FENARDJI*, I. ANGULO** et P. MONGIN

INRA Station de Recherches Avicoles 37380 Nouzilly

* Institut Technique des Petits Elevages, B.P. 2, Birkhadem, Alger (Algérie)

** FONAIAP, Apdo 4653, Maracay

(Vénézuéla)
Ajustements technico-économiques possibles de l'alimentation des volailles dans les pays chauds

Le développement spectaculaire des productions avicoles dans les pays chauds aggrave la situation de dépendance en matières premières alimentaires de beaucoup d'entre eux, ce qui risque de créer des situations conflictuelles face à certains souhaits d'ajustement structurel et aux disponibilités limitées en devises. En tenant compte de ces contraintes et des adaptations techniques possibles à un environnement climatique chaud, peut-on définir des modes d'alimentation des volailles plus adaptés que ceux actuellement utilisés et qui permettraient la poursuite d'une croissance de ces productions?

\section{Résumé}

L'aviculture des régions chaudes doit tenir compte de deux facteurs limitants majeurs : le climat qui freine la consommation énergétique des volailles et modifie l'habitat et les cycles de productions (croissance ralentie, oeufs plus petits...) et l'importation, pour beaucoup de pays chauds, des céréales et du tourteau de soja avec des devises de plus en plus rares.

Les solutions nutritionnelles viables à moyen terme, pour les volailles, sont celles qui tiennent compte de ces deux types de contraintes dans le choix des normes de formulation et qui intégreront l'aviculture dans le développement agro-industriel global de ces pays. Sept exemples expérimentaux illustrent la recherche de solutions adaptées, en collaboration entre l'INRA et plusieurs pays chauds. Pour être efficacement appliquées ces solutions requièrent une adaptation pratique par les professionnels de l'aviculture dans chaque situation.

La distribution ad libitum d'un régime complet laisse peu d'espoir de pouvoir compenser les effets négatifs de la chaleur sur les performances par des ajustements de sa composition. Par contre, certaines erreurs comme l'augmentation de la teneur de l'aliment en protéines de mauvaise "qualité", c'est-à-dire avec des concentrations relativement basses d'acides aminés indispensables digestibles, peuvent aggraver les effets du climat.

Le niveau d'ingestion énergétique faible des poules pondeuses permet d'envisager l'utilisation de régimes dilués, granulés, contenant des quantités plus importantes de sous- produits disponibles localement et ayant une valeur nutritionnelle, comme les issues de céréales.

La combinaison de rythmes lumineux et de systèmes d'alimentation discontinue en supprimant l'accès à la mangeoire quelques heures avant et pendant le pic thermique quotidien permet de maîtriser les mortalités excessives des poulets de chair en période de finition.

Le fractionnement du régime complet ouvre des voies de recherches stimulantes dont deux ont déjà prouvé un intérêt :

- technico-économique, dans le cas de l'alimentation calcique séparée des poules pondeuses qui induit une augmentation de l'ingéré énergétique du matin et une amélioration de la ponte ;

- économique par l'utilisation d'un aliment complémentaire unique pour le poulet et la pondeuse distribué en libre choix avec des céréales graines entières pouvant être produites par l'aviculteur ou acquises à moindre coût (et des coquilles d'huîtres pour la ponte). Cette solution permet de limiter les transports et les gaspillages de matières premières en concentrant l'effort technique sur un seul produit.

La mise au point de modèles d'alimentation alternatifs prenant en compte les rythmes de températures et de lumière existant dans les poulaillers ouverts des pays tropicaux est un domaine d'avenir qui devrait stimuler les échanges scientifiques Sud-Nord. 
Depuis 20 ans, l'aviculture intensive se développe partout dans le monde et particulièrement au sud. Alors que la chaleur est en effet souvent présentée comme une source de difficultés dans les pays tempérés, elle possède aussi des avantages intrinsèques puisqu'elle réduit les coûts de logement des animaux. voire une partie des coûts alimentaires. En outre, les divers types de climats chauds, liés au degré d'humidité de l'air et aux fluctuations nycthémérales de température, doivent être examinés comme autant de cas différents.

L'alimentation des volailles doit être ajustée à ces variations climatiques (Nir 1992) mais aussi à la situation économique des pays où elles sont produites, ce qui est loin d'être toujours pratiqué.

Tandis que les nutritionnistes européens s'éloignent en effet régulièrement du modèle "céréale-soja" en valorisant divers sous-produits et les protéagineux, leurs confrères du sud restent paradoxalement plus conservateurs : des masses croissantes de céréales et de soja sont donc importées du nord, nécessitant des quantités de devises elles-mêmes croissantes. Les chances d'un développement avicole harmonieusement intégré à une valorisation croissante des produits agricoles et sous-produits locaux dépendent à leur tour de trois facteurs essentiels :

- une communication efficace entre les acteurs de la filière avicole et ceux des filières de production des matières premières ;

- une évaluation nutritionnelle précise et constamment actualisée des matières premières disponibles et en développement ;

- un choix raisonné des régimes alimentaires à mettre en oeuvre pour nourrir les volailles.

Des prix justes, des compositions de matières premières précisément évaluées et des spécifications nutritionnelles optimales sont donc les trois "points-clés" de la matrice de programmation linéaire dont l'usage courant devrait dépasser la simple formulation des aliments pour servir d'outil de développement et de communication entre filières.

Il serait utopique de prétendre posséder des solutions ajustées à toutes les situations climatiques et économiques des pays du sud. Nous voulons cependant, par quelques exemples, montrer les opportunités offertes par différents environnements en insistant sur le troisième volet: la recherche de modèles de régimes alimentaires adaptés à des situations technico-économiques spécifiques. Cette recherche prend en compte une différence importante, bien que rarement soulignée, entre pays du nord et du sud à savoir que, en régions tempérées, la stabilisation de l'environnement dans les poulaillers a abouti presque systématiquement à la distribution ad libitum d'un aliment composé unique, complet et équilibré. A contrario, les poulaillers ouverts des pays chauds soumettent les volailles à des fluctuations climatiques quotidiennes plus importantes qui justifient l'étude d'autres types d'alimentation. Les ajustements de composition d'un aliment complet rapportés ici concernent principalement les concentrations énergétique et protéique qui constituent l'essentiel du coût. Des exemples d'alimentation discontinue et d'alimentation fractionnée sont présentés ensuite.

La plupart de ces résultats ont été obtenus dans le cadre d'une collaboration de six années entre la France et six pays chauds (Algérie, Cameroun, Côte d'Ivoire, Cuba, Malaisie et Vénézuéla) soutenue par l'INRA, le Ministère de la Recherche et de la Technologie, le Ministère des Affaires étrangères et le Ministère de la Coopération.

\section{1 / Dilution ou concentration des aliments?}

Choisir la concentration énergétique d'un aliment composé est une décision technicoéconomique. Il n'existe pas en effet de "besoin" énergétique qui s'exprime en termes de concentrations alors que certaines concentrations énergétiques permettent effectivement, dans une conjoncture technique et économique donnée, de produire un oeuf ou un kilogramme de viande au moindre coût.

Dans les pays du sud, des raisonnements aussi simples sont souvent méconnus du nutritionniste de la recherche qui ne maîtrise pas les facteurs de coûts. Le nutritionniste formulateur, quant à lui, a trop souvent recours à des tables et des "normes" établies dans un environnement technico-économique très différent du sien.

Trois questions méritent d'être débattues :

- La chaleur modifie-t-elle les réactions de l'animal face à une variation de la concentration énergétique de son régime?

- Dans quelles limites la concentration énergétique du régime peut-elle être abaissée et quelles sont les conséquences de cette dilution sur les possibilités de valorisation de produits et sous-produits agricoles locaux?

- Une fois choisie la concentration énergétique du régime, quels autres ajustements nutritionnels doivent être opérés en climat chaud?

\section{1 / Effets de la chaleur sur l'adaptation de l'animal à son régime}

\section{a / Adaptation à court terme de la consommation et de la production}

Après la naissance, les capacités de thermorégulation du jeune poussin se développent en quelques jours ; à partir de 3 à 4 semaines d'âge, les volailles ne présentent pas de "zone de neutralité thermique" stricto sensu mais s'adaptent continuellement à leur environnement (Smith et Oliver 1977). Hooper et Richards (1991) ont démontré, par les méthodes du conditionnement opérant, que des poules qui peuvent choisir préferent une 
température de 22 à $24^{\circ} \mathrm{C}$. La mesure de leur comportement montre qu'elles semblent en outre plus motivées à "travailler" pour obtenir un refroidissement de leur température ambiante lorsqu'elles sont exposées au chaud plutôt qu'un réchauffement lorsqu'elles sont exposées au froid.

Les modifications adaptatives du métabolisme énergétique induites par la chaleur (Geraert 1991) ont une efficacité vite saturée, surtout si, comme le suggère cet auteur, la thermogénèse alimentaire (production d'"extra-chaleur" consécutive à l'ingestion d'aliment) est accrue en climat chaud. Au-dessus de $28^{\circ} \mathrm{C}$, la température abdominale augmente en fait avec la température extérieure et avec la quantité d'aliment consommée (Li et al 1992). La seule solution pour l'animal est donc de réduire sa consommation d'énergie.

Cette baisse de consommation alimentaire due à la chaleur a été amplement décrite et modélisée (Mc Donald 1978). Elle suit une progression curvilinéaire, un degré d'augmentation de la température ambiante entre 30 et $35^{\circ} \mathrm{C}$ provoquant une diminution de consommation quatre fois supérieure à celle observée entre 10 et $20^{\circ} \mathrm{C}$ (Picard 1985 ).

Cette diminution de l'ingéré n'est que partiellement responsable de la baisse de production (croissance, ponte, poids des oeufs) enregistrée en climat chaud comme le montrent les expériences d'alimentation appariée réalisées sur poules pondeuses par Smith et Oliver (1972) et sur poulets de chair par Fuller et Dale (1979). Appliquant en effet des réductions analogues de consommation à des animaux soumis à une température optimale (environ $20^{\circ} \mathrm{C}$ ), ces auteurs ont enregistré des baisses de production inférieures à celles dues à la chaleur. Rétablir un niveau d'ingestion supérieur en climat chaud, si tant est que cela soit possible, ne rétablirait donc pas une production maximale.

\section{b / Maintien des capacités d'adaptation à long terme}

Si les baisses de consommation et de production semblent donc inéluctables en cas d'exposition à la chaleur, peut-on penser que celle-ci n'agirait que comme un "frein" n'affectant pas gravement les rendements et maintenant intact le potentiel de production de l'animal ?

Les résultats rapportés dans l'encart 1 montrent que les volailles s'adaptent vite à une modification de la température (ou de l'hygrométrie) de leur environnement et ne semblent pas perdre leurs capacités potentielles de production au cours d'expositions prolongées à des conditions climatiques difficiles. Un autre exemple expérimental a été apporté par Njoya en 1987 (cf Picard et Plouzeau 1989) qui a élevé 300 poulettes dans trois conditions climatiques distinctes $\left(22^{\circ} \mathrm{C}\right.$ et $60 \%$ d'humidité relative, ou $32^{\circ} \mathrm{C}$ et $40 \%$ d'humidité relative, ou $32^{\circ} \mathrm{C}$ et $90 \%$ d'humidité relative) jusqu'à l'âge de 18 semaines. Il a ensuite divisé chaque groupe en trois et exposé, pendant la période de ponte, les animaux de chaque sous-groupe aux trois conditions climatiques. Les résultats obtenus ne font apparaître aucune interaction significative entre les climats de croissance et de ponte sur les performances de production, ce qui montre qu'il existe peu d'effet à long terme du climat. Cette observation confirme celles de l'équipe de Sykes (1986) selon lesquelles l'acclimatation métabolique (variation de la température corporelle) de poules pondeuses exposées quotidiennement à un stress thermique aigu se stabilise au bout de 14 jours.

Plus récemment, les résultats obtenus par Arjona et al (1990) et Teeter et al (1992) sur poulet de chair suggèrent cependant une répercussion métabolique durable (pendant 40 jours chez Arjona et al) des stress thermiques aigus. La nature de l'épreuve de chaleur et du modèle animal peuvent expliquer ces différences. Le modèle poulet de chair à croissance rapide, niveau d'ingestion élevé et composition corporelle relativement grasse (Geraert et al 1992) résiste en effet mal à des conditions climatiques chaudes, surtout si les fluctuations thermiques sont brutales (coup de chaleur). Cela se traduit sur le terrain par de la mortalité à certaines époques (cf encart 4). La poule pondeuse au contraire semble capable de maintenir une production sub-optimale en réduisant la taille des oeufs pondus (Sauveur et Picard 1987) jusqu'à des conditions climatiques très critiques (i.e. $30^{\circ} \mathrm{C}$ de température moyenne) lorsque les autres facteurs d'élevage sont corrects.

\section{c / Conséquences pratiques}

En conséquence de ce qui vient d'être exposé, les baisses de performance liées à la chaleur sont distinctes selon le type de production :

- Un poulet de chair doit être maintenu en élevage plus longtemps (une semaine et plus) avant de pouvoir être commercialisé, ce qui crée un gaspillage alimentaire : par augmentation du besoin total d'entretien : à âge égal, les poulets élevés en climat chaud présentent en effet une efficacité alimentaire meilleure que celle enregistrée en pays tempérés mais elle devient moins bonne si l'on raisonne à poids vif égal.

Le maintien d'un indice de consommation satisfaisant peut être obtenu soit par l'abattage d'un animal plus léger correspondant d'ailleurs souvent au pouvoir d'achat (mais pas aux besoins nutritionnels) des familles tropicales, soit la distribution de régimes relativement concentrés si une telle concentration est économiquement possible. L'intérêt d'un cycle court est renforcé par les risques croissants de mortalité due à la chaleur après six semaines.

Une poule pondeuse, au contraire, pond des œufs plus petits avec une très bonne persistance en milieu tropical. Les oeufs n'y étant en général pas vendus selon leur calibre l'incitation à en augmenter la taille est faible. En revanche, le niveau d'ingestion d'une poule pondeuse étant bas en climat chaud, il existe une possibilité réelle d'optimisation et de recherche sur la concentration et la composition des régimes permettant une production économique d'un grand nombre d'oeufs de poids limité.
Une température élevée entraîne une baisse de la consommation et de la production, non compensable par l'alimentation et plus préjudiciable aux productions à cycle court (poulet). 
Encart 1.

\section{La chaleur agit-elle comme un simple frein ?}

72 poules pondeuses semi-lourdes Isa Brown ont été placées, à l'âge de 18 semaines, dans les cages individuelles de 2 batteries identiques situées dans 2 cellules conditionnées voisines. Tous les animaux ont reçu le même régime alimentaire concentré (3000 kcal EM / kg ; 25,5\% de protéines brutes et $5,7 \%$ de calcium, valeurs mesurées) entre 18 et 66 semaines d'âge. La température ambiante d'une des cellules, initialement de $22^{\circ} \mathrm{C}$, a été progressivement élevée entre 18 et 22 semaines pour atteindre $32^{\circ} \mathrm{C}\left(+1^{\circ} \mathrm{C}\right)$ constants. Elle a été maintenue jusqu'à l'âge de 59 semaines (soit pendant 9 mois) puis brutalement rabaissée à $22^{\circ} \mathrm{C}$, température de la cellule témoin. Les deux graphiques ci-dessous illustrent les principales performances moyennes enregistrées pour chaque période de quatre semaines entre 23 et 66 semaines d'âge.

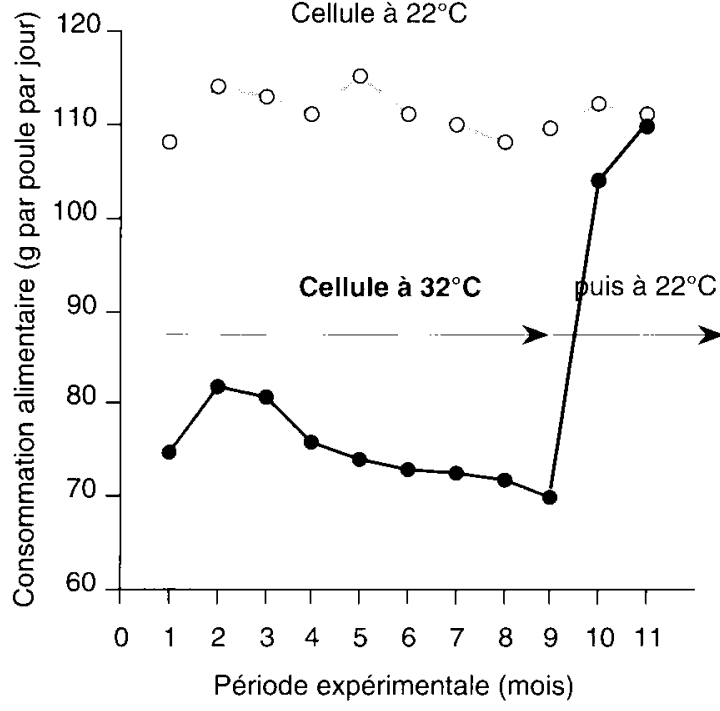

Un écart très important de production de 11,3 $g$ d'oeufjour en moyenne est apparu entre les deux environnements, avec une aggravation progressive au fil du temps. Le retour à une température de $22^{\circ} \mathrm{C}$ a permis aux poules pondeuses qui avaient été exposées à $32^{\circ} \mathrm{C}$ de rattraper, en moins d'un mois, le niveau de production des animaux témoins bien que celui-ci soit encore élevé (supérieur à $50 \mathrm{~g} / \mathrm{j}$ ).
La consommation alimentaire quotidienne a différé d'environ 11 kcal/degré pendant 9 mois consécutifs. Le retour à $22^{\circ} \mathrm{C}$ a effacé complètement cet écart après un délai inférieur à 2 semaines d'ajustement. Au cours de la dernière période, les poules pondeuses préalablement exposées à la chaleur pendant 9 mois ont consommé exactement la même quantité d'aliment que les animaux témoins.

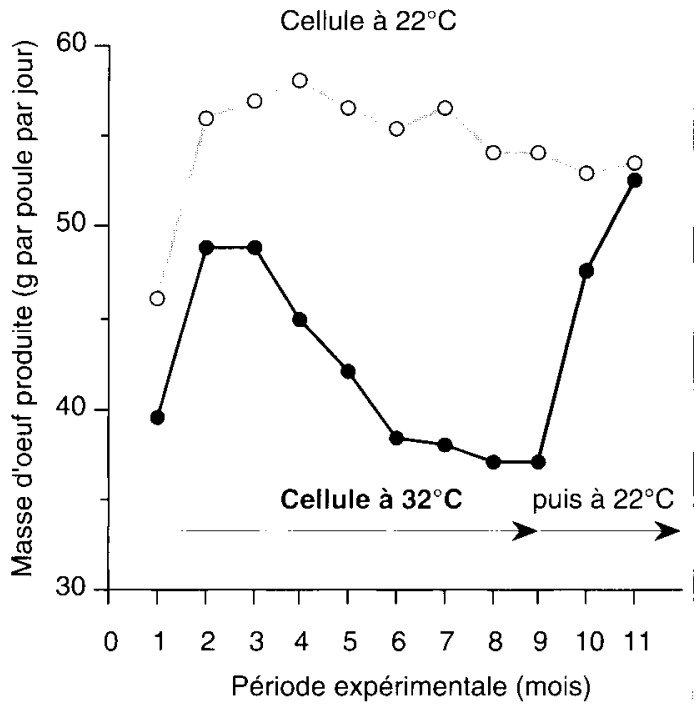

Cet exemple expérimental suggère que les animaux exposés à une température très élevée $\left(32^{\circ} \mathrm{C}\right.$ constants correspond à un climat cyclique variant entre $25^{\circ} \mathrm{C}$ et $40^{\circ} \mathrm{C}$ ) pendant plus de 9 mois consécutifs n'ont rien perdu de leurs capacités de production. Après des délais relativement brefs d'ajustement (1 à 3 semaines), les poules sont capables de compenser complètement des écarts très importants de consommation et de production. Tout se passe comme si la chaleur agissait comme un frein bridant la productivité de l'animal pendant la durée d'exposition.

\section{2 / Dilution énergétique et possibilité de valorisation de produits alimentaires locaux}

Une autre question pratique découlant du paragraphe précédent aurait pu être : peut-on (doit-on) tenter de maintenir l'ingéré énergétique des poulets ou des poules en climat chaud par un ajustement de la composition du régime? De nombreux résultats, parmi lesquels ceux d'El Jack et Blum (1978) sur poules pondeuses et d'Aïn Baziz et al (1990) sur poulets de chair, ont en fait montré que d'importantes modifications de la composition du régime alimentaire ne permettent pas de remédier aux effets de la chaleur (Geraert 1991). Il serait donc illusoire de chercher à agir par cette voie, contrairement à ce qui est affirmé ici et là. 
Le fait qu'une concentration énergétique plus élevée du régime fasse baisser l'indice de consommation quel que soit le climat n'implique pas une correction des effets négatifs de la chaleur.

Ceci ne signifie pas non plus qu'une éventuelle modification du régime ne présente pas d'intérêt économique si elle permet d'utiliser des produits locaux. Il convient donc d'en connaître les effets aussi exactement que possible.

De façon générale, l'importance économique du choix d'une concentration énergétique tient au fait que non seulement l'énergie représente les deux tiers du coût des matières premières d'un aliment pour volailles mais aussi que l'apport de tous les autres nutriments doit être proportionnellement modifié dans l'aliment puisque les animaux adaptent leur ingéré à la concentration énergétique du régime.

Par ailleurs, ce choix exclut ou permet l'utilisation de certaines matières premières et modifie les quantités d'aliment à fabriquer pour un volume de productions animales donné.

Selon la concentration énergétique du régime, des composants spécifiques tels que les parois végétales ou les graisses varient et peuvent avoir des effets propres sur les résultats zootechniques. Enfin, la dilution énergétique modifie les volumes et la composition des matières indigestibles excrétées par les volailles qui, si elles ne sont pas valorisées, polluent l'environnement.

Dans les pays chauds, où une part importante des matières premières destinées aux volailles doit être importée, le choix d'une concentration énergétique comporte donc des aspects stratégiques.

L'alimentation humaine, quant à elle, engendre des masses considérables de sousproduits céréaliers (ex : plus de 800000 tonnes de sous-produits du blé par an en Algérie) dont une bonne partie sert à nourrir des ruminants qui pourraient valoriser d'autres ressources agricoles.

Certaines productions agro-industrielles tropicales (ex : huile de palme ou manioc au Vénézuéla) sont l'objet de projets de développement qui doivent être associés, voire intégrés, à ceux des filières d'élevages, en particulier avicoles.

\section{a / Possibilités de dilution énergétique des régimes}

Les exemples expérimentaux présentés dans l'encart 2 montrent que la poule pondeuse en climat chaud peut valoriser efficacement des régimes très dilués $(2100 \mathrm{kcal} \mathrm{EM} / \mathrm{kg}$ ) contenant beaucoup de sous-produits du blé riches en fibres (la moitié de la ration). $\mathrm{Ce}$ résultat est en accord avec plusieurs travaux antérieurs (voir par exemple El Jack et Blum 1978, Olumu et Offiong 1983, Picard 1985, Picard et al 1987, Shukla et al 1988).
En 1988, Dongmo a démontré dans notre laboratoire que ce type de régime dilué est d'autant mieux valorisé que la poulette le reçoit depuis la phase de croissance (cf Picard et Plouzeau 1989). En outre les variations d'humidité de l'air ne semblent pas modifier ces conclusions (Uzu 1986). La dilution énergétique d'un régime de ponte serait cependant un non-sens économique si le diluant utilisé n'avait aucune valeur nutritionnelle intrinsèque. La dilution entraîne en effet des surcoûts de stockage, de transport et de fabrication à cause de la faible densité physique des matières premières utilisées. Les rations diluées doivent aussi être granulées pour que leur consommation ne soit pas limitée par la capacité d'ingestion de l'animal. Ces divers coûts doivent donc être évalués localement avant que ne soit prônée la diffusion de ce type de régime. Un bilan rigoureux basé sur un ingéré énergétique constant permet seul de mesurer les économies réelles de matières premières importées et de sélectionner les produits locaux valorisables.

\section{b / Actions spécifiques des graisses et des parois végétales}

Les effets de la concentration énergétique de la ration doivent être dissociés de l'action des graisses alimentaires sur la consommation énergétique et la production de chaleur métabolique.

Chez le poulet de chair (Dale et Fuller 1979, 1980) comme chez la poule pondeuse (Daghir 1987, Ramlah et Sarinah 1992), l'addition de lipides au régime, sans modification de l'apport d'énergie métabolisable, se traduit par des augmentations de l'ingéré énergétique et de la production attribuables à un meilleur rendement énergétique des lipides qui induisent une production de chaleur plus faible que les autres nutriments organiques. Dans beaucoup d'essais, cet effet semble exister quelle que soit la température ambiante. Il peut être obtenu indépendamment de la concentration énergétique de l'aliment puisque l'on peut toujours imposer une teneur minimale en graisse (si elle se justifie économiquement) dans n'importe quel type d'aliments.

Les "normes" concernant la teneur en parois végétales des rations pour volailles sont, quant à elles, généralement non fondées car elles sont exprimées en "cellulose brute" et confondent l'imprécision de cette mesure, la méfiance vis-à-vis de certaines matières premières, les effets éventuels de la densité physique du régime sur la prise alimentaire... avec un effet improbable des parois végétales stricto sensu.

Lorsque l'on considère le rôle exact des différents facteurs (concentration énergétique, teneur en graisse du régime, valeur nutritionnelle des sous-produits, granulation d'un aliment...) sur les résultats zootechniques et économiques, il est possible de concevoir des régimes pour volailles dans lesquels l'apport énergétique d'origine tropicale se baserait par exemple sur un mélange d'amidon de tubercules, de sous-produits des céréales consom-

\author{
La dilution \\ énergétique de \\ l'aliment de ponte \\ permet d'utiliser des \\ sous-produits locaux \\ mais nécessite de le \\ granuler : la \\ décision relève \\ surtout de \\ considérations \\ économiques.
}


Encart 2.

\section{Peut-on diluer un régime de ponte granulé en climat chaud?}

L'introduction, à des taux croissants, de sousproduits céréaliers (son de blé) dans un aliment complet pour poule pondeuse fait baisser simultanément la concentration énergétique et la densité physique du mélange. La granulation industrielle permet de corriger cet abaissement de la densité. Dans ces conditions, la poule pondeuse semble être capable d'ajuster sa consommation alimentaire pour maintenir constant son ingéré énergétique et les productions sont peu modifiées.
Les deux séries de résultats expérimentaux rapportés ci-dessous confirment cette faisabilité technique d'une dilution importante du régime, dans des conditions d'environnement contrôlé (température constante de $32^{\circ} \mathrm{C}$ ) comme en climat tropical réel A. Leon et I. Angulo 1992, travail réalisé au Vénézuela). L'intérêt économique et l'applicabilité d'une telle démarche restent cependant à évaluer dans chaque situation locale.
Cellules conditionnées $32^{\circ} \mathrm{C}$ constant 36 poules en cages individuelles par traitement

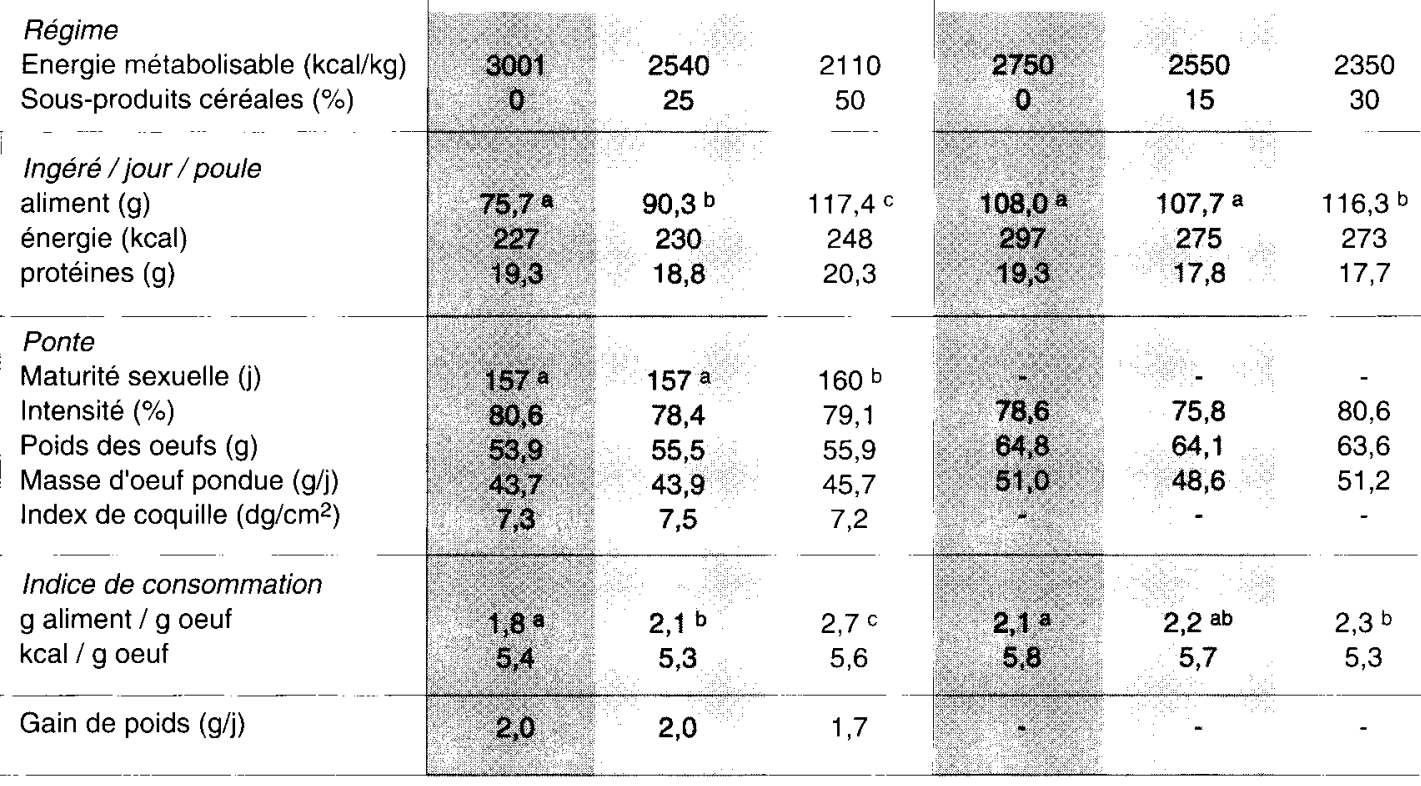

Les valeurs suivies de lettres différentes à l'intérieur d'une même expérience sont significativement différentes $(P<0,05)$
Climat tropical (Vénézuela) 54 poules ( 9 cages de 6 ) / traitement. (Leon et Angulo 1992)

\section{Un excès de protéines alimentaires peut être nocif si le régime n'est pas correctement équilibré en acides aminés indispensables.}

mées par l'homme et d'huiles végétales. Restent alors à trouver les sources des autres nutriments, notamment protéique, ce qui va être discuté maintenant.

\section{3 / Equilibres protéiques}

Il est de pratique courante d'ajuster la teneur en protéines et en acides aminés d'un aliment composé pour volailles à sa teneur en énergie et à la température ambiante afin de maintenir constant l'ingéré quotidien d'acides aminés à un âge donné. Cette pratique sousentend que les animaux utilisent les protéines de l'aliment avec la même efficacité et conservent la même production quelle que soit la température ambiante, ce qui n'est pas le cas.

Est-il donc utile ou non de pratiquer un tel ajustement? Différentes expériences apportent à cette question des réponses divergentes.
Ainsi les travaux de Reid et Weber (1973) sur poules pondeuses ou de Cowan et Michie (1978) sur poulets de chair montrent que cet ajustement est inefficace pour corriger les effets négatifs de la chaleur sur les performances.

Dans sa revue de 1985, Austic suggère prudemment d'ajuster linéairement la composition des aliments en acides aminés indispensables à la température ambiante entre 20 et $30^{\circ} \mathrm{C}$, mais pas au-delà de $30^{\circ} \mathrm{C}$, pour tenir compte des baisses de performances observées chez le poulet et la pondeuse.

Encore s'agit-il là, à notre avis, d'une proposition conservatrice car les performances de production des poulets et des pondeuses sont diminuées pour des températures moyennes nettement inférieures à $30^{\circ} \mathrm{C}$. Cependant $\mathrm{Mc}$ Naughton et Reece (1984) suggèrent qu'une teneur en lysine du régime limitée à 
3,08 g/Mcal empêcherait les réponses des poulets à l'augmentation de la concentration énergétique de l'aliment en climat chaud $\left(26-27^{\circ} \mathrm{C}\right)$. Uzu (1989) démontre aussi que le besoin en méthionine de la poule pondeuse reste élevé en climat chaud et sec, ou chaud et humide, malgré les baisses de performance.

Waldroup (1982) suggère enfin qu'un excès de protéines peut avoir un effet négatif sur le bilan énergétique du poulet en climat chaud en induisant une production de chaleur métabolique excessive due à la dégradation des acides aminés en excès. Il propose en conséquence le développement de régimes à bas taux protéique, rééquilibrés en acides aminés indispensables par l'addition d'acides aminés de synthèse. Les résultats obtenus par Sinurat et Balnave (1985) semblent également suggérer qu'une réduction du rapport [Acides aminés du régime / Energie métabolisable] améliorerait les performances du poulet exposé à la chaleur en finition.

Le travail présenté (encart 3) montre qu'un climat chaud accentue les baisses de performances dues à une sub-déficience en un acide aminé indispensable (ici la lysine) au sein d'un régime hyperprotéique. Il montre aussi que le même excès protéique est sans effet si le régime est équilibré en acides aminés, comme le confirment Barbour et Latshaw (1992) en climat tempéré. Il convient donc d'éviter toujours les excès protéiques associés à une déficience en acides aminés indispensables digestibles .

La situation testée au cours de notre expérience se rencontre souvent dans les pays chauds où les formulateurs ont tendance à imposer des minima protéiques élevés tout en utilisant des matières premières dont la teneur ou/et la disponibilité en acides aminés indispensables est incertaine ou surestimée. Tel est le cas des sous-produits riches en fibres, dont une partie des protéines liée aux parois végétales est indigestible, des farines animales de compositions ou de cuisson incertaines ou bien, comme au Vénézuéla, de sorghos riches en tannins. L'équilibre en acides aminés indispensables digestibles semble donc être un aspect plus critique des rations tropicales que leur teneur en protéines brutes.

\section{4 / Equilibres minéraux}

La chaleur modifie également les équilibres ioniques et minéraux des volailles. L'évaporation pulmonaire induit en effet une alcalose respiratoire dont l'impact réel sur les productions est encore mal connu mais qui affecte entre autres la qualité de la coquille de l'oeuf (Sauveur et Picard 1987).

La distribution d'eau carbonatée aux poules pondeuses (Odom et al 1985) améliore partiellement la qualité des coquilles. L'addition de $1 \%$ de $\mathrm{NH} 4 \mathrm{Cl}$ et $0,5 \%$ de $\mathrm{Na} \mathrm{HCO} 3$ à la ration des poulets de chair améliore significativement la croissance mais ne compense que très partiellement les effets négatifs de la chaleur (Teeter et al 1985).
Encart 3.

\section{Equilibre protéique d'un régime de croissance en climat chaud (Air Tahar et Picard 1987)}

Le rééquilibrage protéique des aliments pour volailles dans les pays chauds pose deux questions complémentaires:

- Faut-il concentrer les régimes en acides aminés pour corriger complètement la diminution d'ingéré liée à la chaleur?

- Ne risque-t-on pas, par un excès de nutriments protéiques, d'aggraver la production de chaleur métabolique?

L'expérience suivante a été réalisée sur 192 poussins de chair Shaver mâles répartis à l'âge de 8 jours dans deux batteries de 96 cages individuelles identiques dans deux cellules conditionnées voisines.

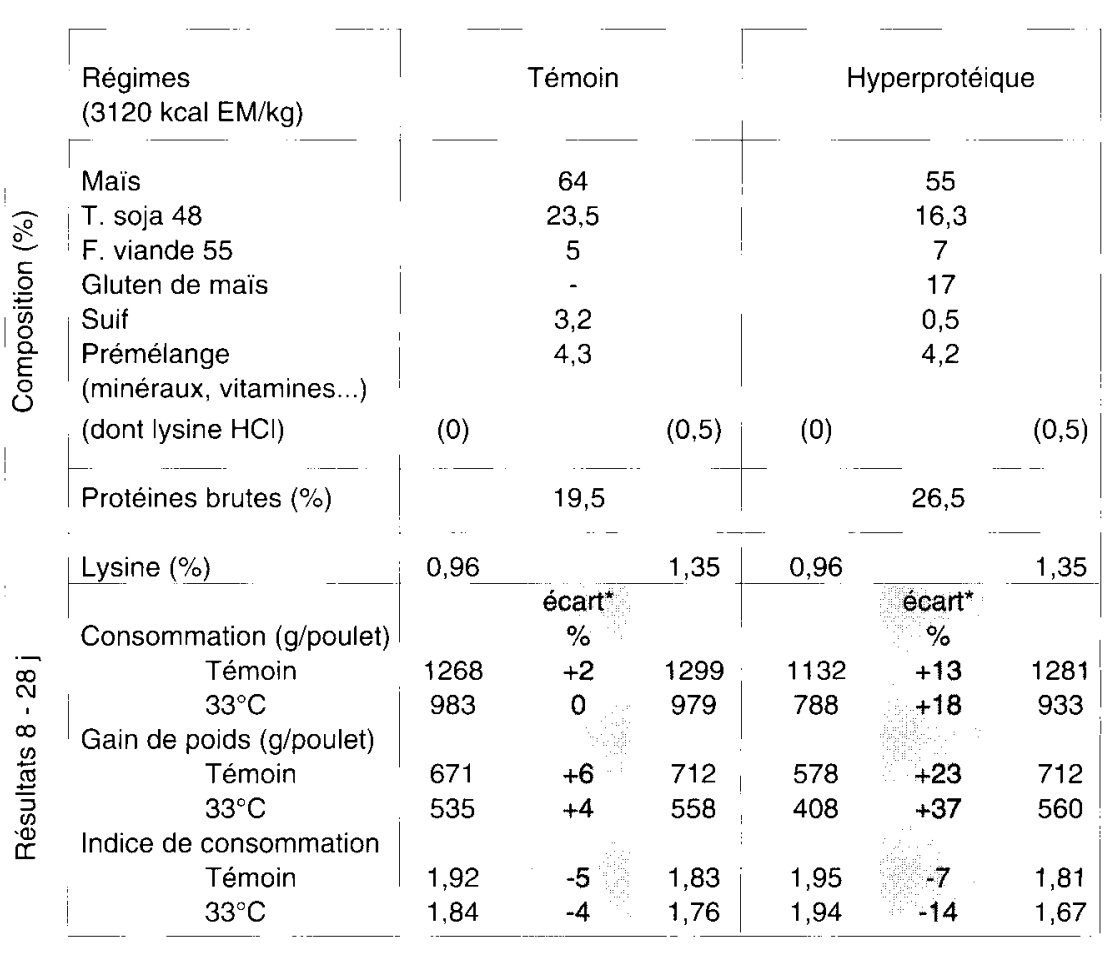

Témoin : $32^{\circ} \mathrm{C}-1^{\circ} \mathrm{C}$ par jour de 8 à 20 j puis $20^{\circ} \mathrm{C}$ constant. * Effet de l'addition de lysine $\mathrm{HCl}$.

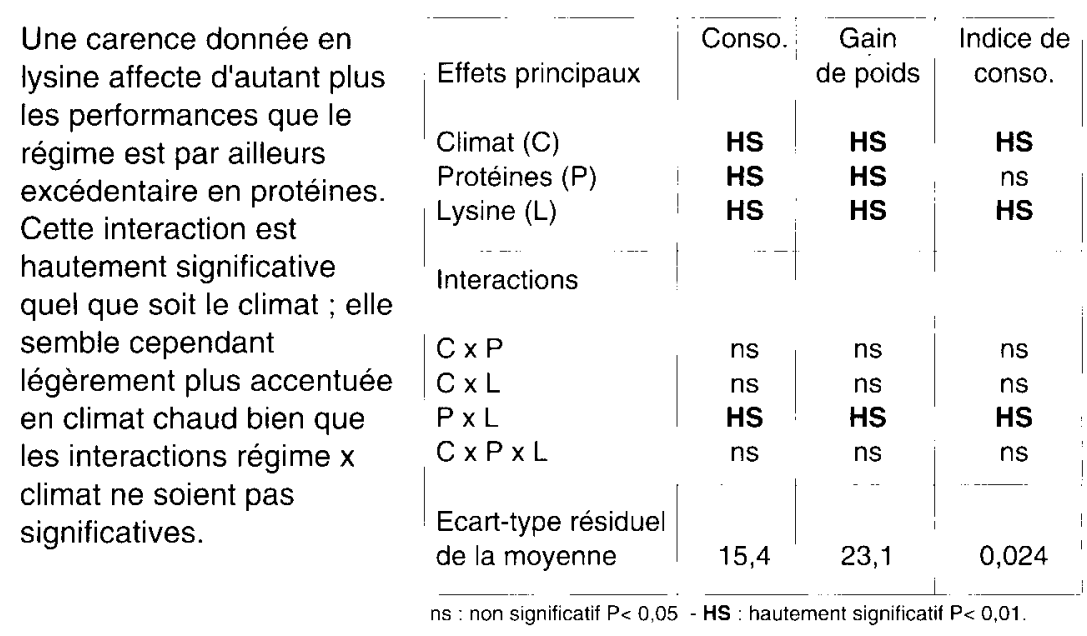

Cette expérience suggère q'un apport supplémentaire de protéines ou de lysine ne permet pas de corriger le retard de performances de croissance dû à la chaleur mais q'un excès de protéines n'est nocif que si le régime est déséquilibré en acides aminés indispensables. 
Dans des conditions de stress thermique, l'équilibre minéral est affecté par une augmentation des pertes urinaires et fécales de plusieurs minéraux (Belay et al 1992). L’addition de chlorure de potassium à l'aliment ou à l'eau de boisson peut améliorer la résistance du poulet de chair à la chaleur (Smith et Teeter 1987). Cet effet du chlorure de potassium pourrait être lié aux variations de calcium ionique plasmatique dont la baisse semble proportionnelle à l'importance du stress thermique (Ait Boulahsen et al 1992). Une diminution de la concentration du calcium dans le régime, un jeûne de 24 heures, la distribution de chlorure de potassium accroissent sensiblement la résistance des volailles aux stress thermiques aigus. La transposition de ces expériences physiologiques en recommandations pratiques pour l'alimentation de volailles soumises à un environnement constamment chaud nécessite encore des travaux.

\section{5 / En bref...}

Les modifications de composition d'un aliment complet distribué ad libitum au poulet ou la poule pondeuse se sont révélés à ce jour inefficaces à compenser les effets négatifs de la chaleur sur la consommation alimentaire et les productions.

Sur le plan technique, la dilution énergétique des régimes de ponte est possible en climat chaud si les aliments sont granulés : la décision dépend de la conjoncture économique et de la stratégie de développement agricole suivie.

Un excès de protéines alimentaire peut être nocif si le régime n'est pas correctement équilibré en acides aminés indispensables.

Les deux dernières remarques appellent à un effort, localement, d'évaluation et de quantification de la valeur nutritionnelle exacte de matières premières et de l'impact économique précis des caractéristiques des formules. C'est un travail d'application pour lequel tous les "outils" existent. La première remarque suggère un travail de recherche : en oubliant la notion "d'aliment complet distribué ad libitum" quelles nouvelles (?) stratégies nutritionnelles pourrait-on étudier dans un contexte tropical ?

\section{2 / Alimentation discontinue}

Dans la région de Maracaibo au Vénézuéla, les jours de chaleur $\left(39\right.$ ou $40^{\circ} \mathrm{C}$ l'après midi avec une hygrométrie supérieure à $80 \%$ ), on peut trouver au sein d'un élevage 3 à 4000 poulets de 7 semaines morts le soir. Cette constatation est tellement usuelle qu'un vétérinaire a fait établir des abaques qui indiquent, en fonction de la température relevée à $10 \mathrm{~h}$ du matin et de l'âge des animaux, le nombre probable de morts par la chaleur le soir.

Ceci permet au moins de ne pas laisser échapper les effets supplémentaires d'une maladie infectieuse toujours possible. Les ani- maux qui meurent sont parmi les plus gros, leur température rectale au moment de la mort est voisine de $46^{\circ} \mathrm{C}$.

Ainsi se présente l'effet le plus coûteux de la chaleur car les animaux qui meurent dans ces conditions ont déjà consommé l'essentiel de leur aliment et constituent une perte économique sèche. Quels sont les moyens de lutter contre de tels stress thermiques? La simple suppression temporaire de l'aliment est-elle efficace?

\section{1 / Alimentation discontinue du poulet de chair}

Les premières tentatives de suppression de l'aliment pendant la période chaude de la journée se sont heurtées à deux types d'échecs :

la distribution de l'aliment le soir se faisant de manière manuelle, mangeoire après mangeoire, les animaux s'entassent sur les premières mangeoires servies. Il faut donc adopter une technique simple permettant de ré-alimenter un poulailler de 10000 poulets en quelques minutes : mangeoires ou chaînes suspendues que l'on abaisse, ou couvercle que l'on enlève rapidement.

- le temps d'accès à l'aliment, compte tenu du jour tropical de 12 heures, est trop court et la vitesse de croissance est freinée d'environ 3 jours : l'éclairage et la distribution d'aliment nocturnes permettent de compenser complètement le retard de croissance.

Les résultats obtenus par cette technique simple de restriction alimentaire (encart 4) montrent une suppression complète de la mortalité supplémentaire pendant les mois les plus chauds de l'année. Ce résultat pratique est en accord avec les données récemment publiées par Francis et al (1991) relatives à des poulets de 33 jours placés en stress thermique aigu $\left(35-40^{\circ} \mathrm{C}\right)$ quotidien pendant 4 heures par jour. La suppression de la lumière ou de l'aliment 2 heures avant le stress induit une réduction significative de l'augmentation de température rectale. Par opposition, les variantes nutritionnelles majeures expérimentées (teneurs du régime en protéines, lipides, glucides et énergie) n'affectent pas significativement la variation de température rectale.

May et Lott (1992) ont aussi mesuré les variations temporelles de consommation alimentaire de poulets soumis pendant 16 jours à une température cyclique $\left(24 / 35^{\circ} \mathrm{C}\right)$ ou constante $\left(24^{\circ} \mathrm{C}\right)$. Ils ont observé que la baisse d'ingéré énergétique intervient régulièrement pendant la deuxième moitié du nycthémère, c'est-à-dire après le pic thermique. Le poulet de chair ne semble donc pas capable d'anticiper l'augmentation de la chaleur en diminuant son ingéré énergétique avant le pic, alors qu'il est parfaitement capable d'anticiper une période de retrait de l'aliment en surconsommant pendant les deux heures qui précèdent, si ce retrait est synchronisé avec un rythme d'éclairement (May et Lott 1992b). 


\section{Distributions alimentaires discontinues chez le pouler de chair et la poule pondeuse}

Les volailles ne semblent pas capables de prévoir les fluctuations nycthémérales de températures ; tout du moins elles n'anticipent pas le pic thermique quotidien en diminuant leur prise alimentaire préalable. Le décalage entre consommation de l'aliment et production de chaleur semble responsable des malaises hyperthermiques observés en début d'après-midi chez les poulets de chair et des mortalités parfois importantes observées le soir, après l'âge de 5 semaines, en milieu tropical.

L'exemple de terrain illustré par le graphique ci-contre montre que la suppression de l'aliment de $9 \mathrm{~h}$ à $17 \mathrm{~h}$ permet d'éliminer l'excédent de mortalité observé en avril au Vénézuela (période la plus chaude, environ $28^{\circ} \mathrm{C} / 39^{\circ} \mathrm{C}$ ). L'éclairement du poulailler pendant la nuit permet de maintenir une vitesse de croissance égale à celle des animaux nourris ad libitum. Essai industriel réalisé dans l'état de Zulla (Vénézuela) en 1987 par Angulo et Urdaneta.

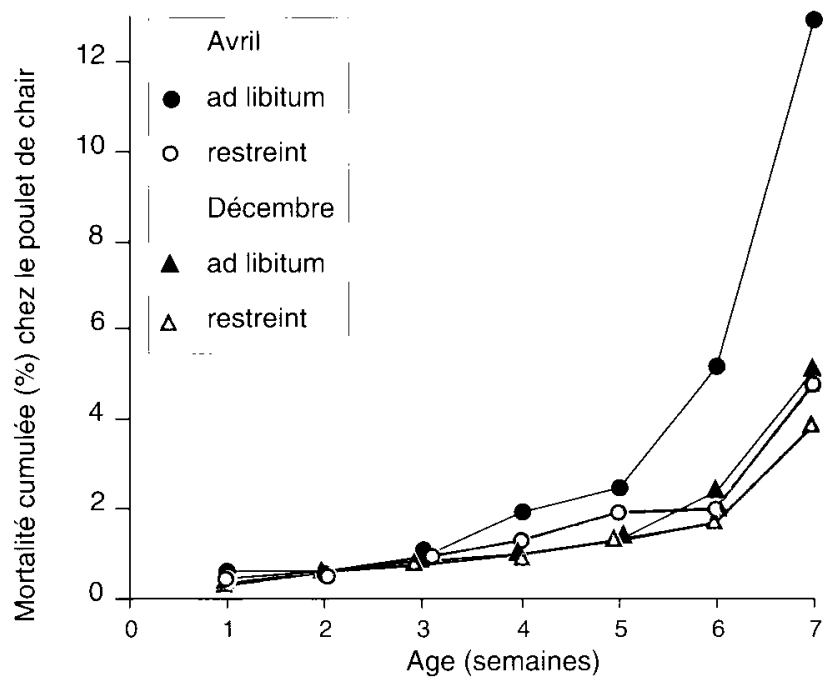

Chez la poule pondeuse, la même suppression de l'aliment en milieu de journée agit peu sur les performances entregistrées en climat artificiel cyclique $\left(26^{\circ} \mathrm{C}\right.$ la nuit avec un pic thermique à $39^{\circ} \mathrm{C}$ à $16 \mathrm{~h}$ ). En milieu tropical naturel, une amélioration significative de la productivité (légère baisse de la consommation et légère augmentation de la masse d'oeuf produite) a été enregistrée.

\begin{tabular}{|c|c|c|c|c|c|c|}
\hline & \multicolumn{3}{|c|}{$\begin{array}{l}\text { Climat artificiel } 26 / 39^{\circ} \mathrm{C} \\
\text { (Ameur et Picard } 1991 \text { ) }\end{array}$} & \multicolumn{3}{|c|}{$\begin{array}{l}\text { Climat tropical naturel - Malaisie } \\
\text { (Ramlah et Jalaludin 1989) }\end{array}$} \\
\hline & $\begin{array}{l}\text { Témoin } \\
\text { ad libitum }\end{array}$ & $\mathrm{Ecart}_{\%}$ & $\begin{array}{l}2 \text { repas } \\
5-9 \mathrm{~h} \text { et } \\
16-21 \mathrm{~h}\end{array}$ & $\begin{array}{l}\text { Témoin } \\
\text { ad libitum }\end{array}$ & $\begin{array}{c}\text { Ecart } \\
\%\end{array}$ & $\begin{array}{l}2 \text { repas } \\
8-11 \mathrm{~h} \text { et } \\
17-20 \mathrm{~h}\end{array}$ \\
\hline Ingéré alimentaire $(\mathrm{g} / \mathrm{j} /$ poule) & 86,3 & $-1,5$ & 85,0 & 116,7 & $-5,2$ & 110,6 \\
\hline Ingéré énergétique (kcal/j/poule) & 232 & $-1,5$ & 228 & 315 & $-5,2$ & 299 \\
\hline Ingéré protéique $(\mathrm{g} / \mathrm{j} /$ poule) & 14,5 & $-1,5$ & 14,2 & 17,5 & $-5,2$ & 16,6 \\
\hline Intensité de ponte $\overline{(\%)}$ & $8 \overline{86,2}$ & $-0,6$ & $\overline{85}, 6$ & 74,3 & $+0,7$ & 74,8 \\
\hline Poids moyen des oeufs $(\mathrm{g})$ & $\overline{53,1}$ & 0 & 53,1 & 59,3 & $+3,2$ & 61,2 \\
\hline Masse d'oeuf produite (g/j/poule) & $\overline{45,4}$ & $-0,5$ & $\overline{45,2}$ & 44,1 & $+3,9$ & $45 \overline{8}$ \\
\hline Index de coquille $\left(\mathrm{dg} / \mathrm{cm}^{2}\right)$ & 7,7 & $+3,9$ & 8,0 & - & $-\cdots$ & - \\
\hline Indice de conso. alimentaire $(\mathrm{g} / \mathrm{g})$ & $1, \overline{9}$ & $-1,0$ & 1,88 & 2,65 & $-9,1$ & 2,41 \\
\hline Indice de conso. énergétique $(\mathrm{kcal} / \mathrm{g})$ & 5,09 & $-1,0$ & 5,04 & 7,15 & $-9,1$ & $6, \overline{51}$ \\
\hline Variation du poids vif ( $\mathrm{g} / \mathrm{j} / \overline{\text { poule }})$ & $-0,6$ & 0 & $-0,6$ & $+0,2$ & - & $+0,6$ \\
\hline
\end{tabular}

\section{2 / Alimentation discontinue chez la poule pondeuse}

L'application de la même technique à la poule pondeuse ne semble pas modifier sensiblement les performances dans les conditions d'un climat artificiel cyclique $26 / 39^{\circ} \mathrm{C}$ (encart 4). Aucune différence significative de production n'est en effet mesurée entre une alimentation continue et deux périodes d'accès de 4 et 5
Encart 4. 


\section{Alimentation calcique séparée en climat chaud (Picard et al 1987)}

La distribution séparée d'une source de calcium particulaire comme des coquilles d'huîtres fragmentées et calibrées permet aux poules pondeuses d'exprimer l'appétit calcique spécifique lié pendant quelques heures seulement au dépôt de la coquille de l'oeuf (Sauveur et Mongin 1974). La teneur en calcium du régime de base affecte grandement l'ingestion totale de calcium et d'énergie comme le montre l'expérience suivante.

\begin{tabular}{|c|c|c|c|c|}
\hline Composition (\%) & & nel & Régime II & Régime III \\
\hline Maïs & & & 65,2 & 67,0 \\
\hline Tourteau de soja 48 & & & 23,9 & 24,5 \\
\hline Son de blé & & & 5,5 & 5,6 \\
\hline Carbonate de calcium & & & 2,6 & 0 \\
\hline Phosphate bi-calcique & & & 1,7 & 1,8 \\
\hline Prémélange & & & 1,1 & 1,1 \\
\hline Distribution de coquilles d'huîtres & 0 & + & + & + \\
\hline onsommation énergie (kcal/j/poule) & & & & \\
\hline Période $1-24^{\circ} \mathrm{C}$ & $279^{a b}$ & $270^{a}$ & 292 bc & $297^{\mathrm{C}}$ \\
\hline $\begin{array}{l}\text { Période } 2-33^{\circ} \mathrm{C} \\
\text { Période } 3-24^{\circ} \mathrm{C}\end{array}$ & $\begin{array}{r}219^{a} \\
280^{a}\end{array}$ & $\begin{array}{l}223^{a b} \\
282^{a}\end{array}$ & ${ }_{308^{b}}^{237^{b}}$ & $\begin{array}{r}234^{a b} \\
308^{b}\end{array}$ \\
\hline Sonsommation calcium (g//jpoule) & $-\cdots$ & 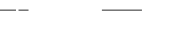 & & \\
\hline Période $1-24^{\circ} \mathrm{C}$ & $4,7^{b}$ & $6,6^{\mathrm{a}}$ & $5,0^{b}$ & $4,8^{b}$ \\
\hline $\begin{array}{l}\text { Période } 2-33^{\circ} \mathrm{C} \\
\text { Période } 3-24^{\circ} \mathrm{C}\end{array}$ & ${ }^{3.7^{a}} 4,7^{b}$ & $5.2^{\mathrm{b}} 6.4^{\mathrm{a}}$ & $3.7^{a}{ }^{a}, 9^{b}$ & $3.1^{a}$ \\
\hline lasse d'oeuf produite ( $\mathrm{g} / \mathrm{j} / \mathrm{poule})$ & & & & $-\ldots$ \\
\hline Période $1-24^{\circ} \mathrm{C}$ & $55,1^{b}$ & $50,5^{\mathrm{a}}$ & $57,0^{b}$ & $59,2^{b}$ \\
\hline $\begin{array}{r}\text { Période } 2-33^{\circ} \mathrm{C} \\
\text { Période } 3-24^{\circ} \mathrm{C}\end{array}$ & $\begin{array}{l}38,9^{a} \\
47,9^{a}\end{array}$ & $\begin{array}{l}38,9^{\mathrm{a}} \\
45,3^{\mathrm{a}}\end{array}$ & $\begin{array}{l}44,7^{\mathrm{b}} \\
52,7^{\mathrm{b}}\end{array}$ & $\begin{array}{l}43,5^{\mathrm{b}} \\
54,0^{\mathrm{b}}\end{array}$ \\
\hline 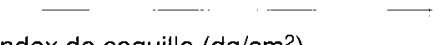 & & - - & -- & \\
\hline $\begin{array}{l}\text { dex de coqualle }\left(\mathrm{dg} / \mathrm{Cm}^{2}\right) \\
\text { Période } 1-24^{\circ} \mathrm{C}\end{array}$ & 8,1 & 8,1 & 7,9 & 8,1 \\
\hline $\begin{array}{r}\text { Période } 2-33 \mathrm{C} \\
\text { Période } 3-24^{\circ} \mathrm{C}\end{array}$ & $\begin{array}{l}7.9^{a b} \\
8.0\end{array}$ & $8,2^{a}$ & $\begin{array}{r}7.7 \mathrm{bc} \\
7.8\end{array}$ & $\begin{array}{l}7.4^{c} \\
8.0\end{array}$ \\
\hline
\end{tabular}

Sur une même ligne, les valeurs suivies de lettres différentes sont significativement différentes à $P<0,05$.
Au cours de trois périodes successives de trois mois, des poules pondeuses (24/traitement) sont exposées à un climat tempéré $\left(24^{\circ} \mathrm{C}\right.$ constant) puis très chaud $\left(33^{\circ} \mathrm{C}\right.$ constant) puis tempéré $\left(24^{\circ} \mathrm{C}\right.$ constant). On constate que la distribution supplémentaire de coquilles d'huîtres avec un régime de base complet (I) conduit à une consommation de calcium plutôt préjudiciable aux performances. Au contraire, lorsque l'aliment de base (III) est complètement dépourvu de carbonate de calcium, l'ingéré de calcium en période chaude est insuffisant pour assurer une qualité de coquille optimale. Le régime de base (II) apportant environ $1 \%$ de calcium permet d'obtenir les meilleurs résultats. L'intérêt de l'alimentation calcique séparée en climat chaud tient surtout à la surconsommation énergétique d'environ $8 \%$ qui se traduit par un gain significatif de production d'oeufs. Cette différence d'ingéré concerne principalement la consommation du matin, la haute teneur en calcium des régimes habituels de ponte ayant un effet négatif sur la consommation alimentaire lorsque les animaux n'ont pas besoin de calcium. ment significative de la production d'oeufs et de l'efficacité alimentaire lorsque l'aliment est retiré pendant 11 heures par jour.

La restriction alimentaire devrait en outre faire l'objet d'une étude combinée avec une réévaluation des rythmes lumineux optimaux pour la poule pondeuse en poulailler tropical ouvert.

En résumé, la mortalité due à la chaleur peut être atténuée chez le poulet de chair par une restriction alimentaire préventive établie 3 à 4 heures avant le pic thermique. L'application de cette technique chez la poule pondeuse ne se justifie que dans des conditions climatiques extrêmes et en combinaison avec une réévaluation des programmes lumineux.

\section{3 / Alimentation fractionnée}

La disponibilité constante d'un aliment unique, complet et granulé, à défaut de toute autre "distraction", ne correspond évidemment pas à la situation originellement offerte aux représentants de l'espèce poule. Le tube digestif et le comportement alimentaire des volailles les prédisposent au contraire à la recherche d'une alimentation variée et irrégulièrement accessible. Dans les élevages bien maîtrisés des pays tempérés où l'on a réussi à limiter les variations de l'environnement, le mode d'alimentation unique a cependant fait ses preuves. Les élevages ouverts des pays chauds exposent les animaux à des fluctuations plus importantes du milieu dont la chaleur mais aussi l'humidité, la lumière, le vent sont des composants majeurs. 
Chercher à redonner quelques "degrés de liberté" à l'animal dans ses choix et ses rythmes de consommation alimentaire est une démarche stimulante susceptible de faire apparaitre des solutions originales. Les quelques exemples présentés dans ce paragraphe ne sont à notre avis que les prémices d'une recherche basée sur l'observation et la créativité, nécessitant des moyens peu sophistiqués, qui pourrait se développer efficacement dans les pays chauds.

\section{1 / Alimentation calcique séparée}

Les jours où elles forment la coquille d'un oeuf, les poules pondeuses expriment pendant les trois ou quatre dernières heures de la période diurne un appétit spécifique pour le calcium qui a fait l'objet d'études physiologiques approfondies (Sauveur et Mongin 1974). La distribution permanente d'un aliment riche en calcium est donc inutile à la fabrication de la coquille de l'oeuf si l'animal dispose d'une source concentrée de calcium pendant la période d'appétit calcique spécifique. Toutefois Sauveur (1992) suggère de maintenir une concentration de $1 \%$ de calcium dans l'aliment de base afin d'assurer une consommation minérale suffisante les jours où il n'y a pas d'oeuf dans le tractus génital de la poule et donc pas d'appétit calcique spécifique. Cette proposition est d'ailleurs confirmée par les résultats de l'expérience présentée à l'encart 5 où le lot ne recevant aucun carbonate de calcium pulvérulent dans son régime de base montre, en période chaude, un abaissement de solidité de la coquille de l'oeuf en dépit d'un apport à volonté de coquilles d'huîtres.

Mais l'intérêt de l'alimentation calcique séparée tient surtout aux améliorations d'ingérés énergétiques qu'elle entraîne comme l'avaient déjà observé Cabrera et al (1982). Si, en climat tempéré, elles constituent plutôt un handicap de la méthode, ces augmentations d'ingéré permettent, en climat chaud, une amélioration significative de la ponte (encart 5). Cet effet positif a été retrouvé par Uzu (1988) en températures chaudes et humides.

En dehors de la période d'appétit calcique spécifique, le carbonate de calcium semble exercer un effet légèrement dépressif sur l'appétit de l'animal (Hull et Scott 1969). La comparaison des ingérés énergétiques du matin et du soir met d'ailleurs en évidence une augmentation significative de la consommation d'énergie le matin (Picard et al 1986).

Il est donc possible que cette technique soit encore plus efficace en climat chaud réel cyclique qu'en condition expérimentale constamment chaude, car la possibilité de consommer de l'énergie le matin (du fait de l'absence de calcium) est alors accrue avec la diminution de température.

Sur le plan économique, supprimer $8 \%$ de carbonate de calcium dans un aliment permet d'offrir aux animaux une ration plus concentrée pour le même prix. On pourrait également envisager une étude de dilution énergétique comparable à celle illustrée par l'encart 2 mais en situation d'alimentation calcique séparée.

Toutefois la mise en pratique de l'alimentation calcique séparée nécessite certains ajustements matériels si les poules se trouvent en cages, de façon à ce qu'elles puissent disposer simultanément de deux sources alimentaires. Parmi les solutions possibles, le mélange d'une source de calcium particulaire dans un aliment en farine est réalisable mais comment s'assurer que toutes les poules d'une même cage disposent d'une quantité suffisante de coquille pendant les quelques heures critiques? Une autre solution est le recours à deux aliments distincts tel qu'exposé ci-dessous.

\section{2 / Régimes "Dual" matin/soir pour poules pondeuses}

Les premières études en ce domaine ont été conduites en climat tempéré par Sauveur et Clavreul (1984) qui utilisaient des aliments différents matin et soir en fonction de la cyclicité des besoins en minéraux des poules pondeuses : aliment riche en calcium et pauvre en phosphore le soir, riche en phosphore et pauvre en calcium le matin. Plus simplement, la seule teneur en calcium peut être modifiée : c'est ce qui a été testé en milieu tropical. L'expérience s'est alors révélée plus concluante en conditions réelles à Cuba qu'au laboratoire en France (encart 6).

L'essai cubain (réalisé à l'Institut de Recherches Avicoles de La Havane par Juana Rodriguez en 1991 dans le cadre d'un programme FAO animé par les auteurs) confirme l'augmentation bénéfique de l'ingéré énergétique lorsque les poules reçoivent une alimentation différenciée au cours de la journée : régime pauvre en calcium le matin et régime riche en calcium le soir. La tendance des animaux à consommer plus d'énergie le matin que le soir est également observée dans l'essai réalisé en France en température constante mais le bilan sur 24 heures n'est alors pas affecté par le type d'alimentation. Deux hypothèses peuvent expliquer cette différence entre les deux essais :

- le régime du soir riche en calcium est distribué nettement plus tard à Cuba et ne représente qu'environ $1 / 3$ de l'ingéré quotidien contre la moitié en France ;

- les températures cubaines sont cycliques alors que celles testées dans l'essai français sont constantes.

L'importance de ce dernier point semble corroborée par le fait que lors d'une répétition de l'essai cubain en période hivernale (climat tempéré) la distribution de régime dual n'a pas permis de stimuler l'ingéré énergétique. La distribution de deux régimes différents (ou plus ?) ne pose pas de problème pratique majeur dans les élevages de ponte où l'on est habitué à distribuer l'aliment plusieurs fois par jour. Cet exemple limité au calcium mériterait donc d'être approfondi par l'étude de régimes ayant des caractéristiques nutritionnelles plus contrastées en modifiant simultanément les programmes d'éclairement lorsque c'est possible.
L'alimentation calcique séparée permet d'augmenter l'ingéré énergétique et la production des poules pondeuses en climat chaud. 
Encart 6.

\section{Régimes "Dual" pour poules poncieuses}

L'alimentation calcique séparée (cf encart 5) induit une augmentation de l'ingéré énergétique du matin qui peut être favorable en période chaude. Une difficulté pratique de cette méthode est la distribution séparée du calcium particulaire en cages avec le risque d'une forte hétérogénéité individuelle de consommation de calcium. La distribution de régimes "Dual" consiste à formuler des aliments différents pour le matin et pour le soir, le carbonate de calcium étant principalement ajouté au régime du soir. Cette technique revient donc à offrir un régime beaucoup plus concentré en énergie (> $3000 \mathrm{kcal} \mathrm{EM} / \mathrm{kg}$ ) le matin et dilué le soir par du carbonate de calcium. Les résultats obtenus en climats artificiels $\left(22\right.$ ou $33^{\circ} \mathrm{C}$ constant ; essai 1) confirment la tendance à une surconsommation de l'énergie le matin lorsque les poules reçoivent un régime "Dual". Cependant, dans les conditions de cette expérience, l'ingéré énergétique global de la journée reste identique à celui observé avec un seul aliment de composition constante. Le même type de régime "Dual" réalisé en climat tropical réel à Cuba a induit en revanche une surconsommation énergétique et une amélioration de la ponte de poules légères lorsque le pic de ponte doit intervenir en période estivale.

\begin{abstract}
Essai $1: 144$ poules Isa Brown sont réparties à 18 semaines dans deux batteries identiques de 72 cages individuelles situées dans deux cellules conditionnées voisines (l'une à $22^{\circ} \mathrm{C}$ constant, l'autre à $32^{\circ} \mathrm{C}$ constant). Elles reçoivent soit un aliment constant (contenant $2670 \mathrm{kcal}$ EM/kg, 17\% de protéine brute et $4,4 \%$ de calcium), soit le même régime sous forme "dual" matin et soir. Résultats moyens de la période 24-44 semaines.

Effet climat significatif pour tous les critères ; effet régime significatif pour ingéré matin/soir ; aucune interaction significative.
\end{abstract}

Essai 2 : 168 poules légères (type Shaver) reçoivent trois régimes alimentaires (14 répétitions de 4 poules par traitement) pendant 12 mois de ponte débutant en mai à Cuba : un régime témoin maïs soja à $2830 \mathrm{kcal}$ EM/kg et $16 \%$ de protéine brute est distribué selon le plan de rationnement quantitatif cubain, soit ad libitum, soit sous forme "Dual" (2/3 régime bas en calcium, 1/3 régime dilué par le carbonate de calcium à partir de $15 \mathrm{~h}$ le soir -Rodriguez et al 1991). Sur une même ligne, les valeurs suivies de lettres différentes sont significativement différentes à $P<0,05$.

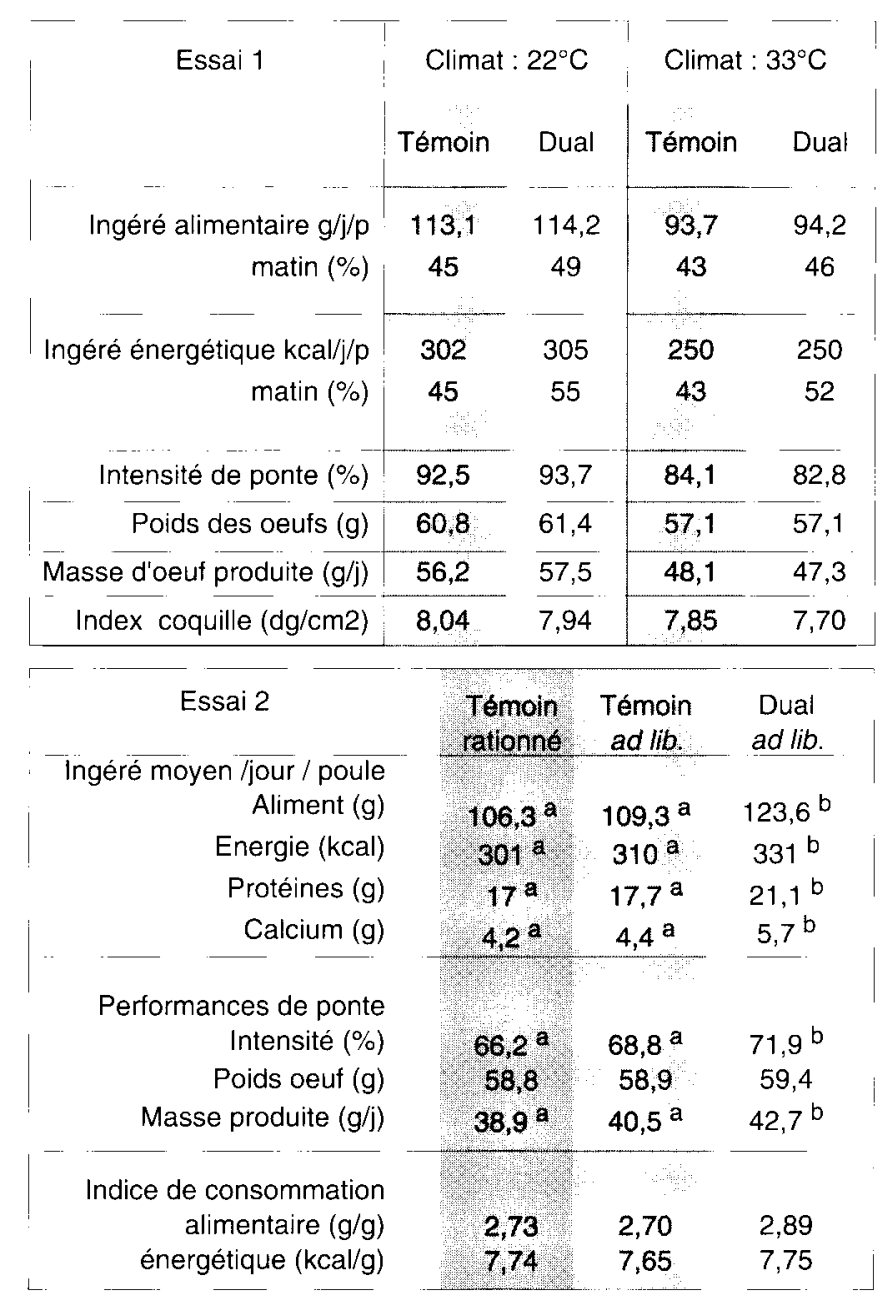

\section{3 / Alimentation en "libre choix"}

Les capacités de choix alimentaires des volailles ont été démontrées depuis longtemps (Hughes 1984). On sait en effet que les animaux en situation de "libre choix", c'est-à-dire recevant simultanément plusieurs aliments de compositions différentes, sont généralement capables d'équilibrer leur ration et de croitre ou pondre correctement. Il est toutefois usuel d'observer une légère détérioration du rendement énergétique de l'aliment que l'on retrou- ve d'ailleurs dans la plupart des résultats présentés dans l'encart 7. Cumming (1992) fait observer que certaines conditions précises de "l'apprentissage" (taille du groupe de volailles supérieure ou égale à 8) et de présentation des différentes fractions du régime (dans des mangeoires semblables côte à côte ou bien grossièrement mélangées) peuvent améliorer sensiblement les résultats pratiques d'une alimentation en libre choix.

En climat chaud Scott et Balnave (1988, 1989) montrent que des poulettes recevant une 


\section{Alimentation en libre choix des céréales graines entières}

(collaboration avec l'équipe technique de I'UFAC, le CIRAD / IEMVT - H. Guérin et I'IDESSA en Côte d'Ivoire - T. Yo)

Le transport et le stockage des graines, la fabrication et la conservation des aliments posent parfois plus de problèmes que l'équilibre nutritionnel des rations. Le succès d'un aliment complémentaire unique granulé et bien fabriqué qui apporterait tout sauf la céréale pour les poulets de chair, et tout sauf la céréale et la source particulaire de calcium pour la poule pondeuse, dépend des capacités de sélection des volailles ou bien de l'application d'un plan de rationnement.

Poules pondeuses en climat tempéré chaud 20-44 sem.

\begin{tabular}{|c|c|c|c|c|}
\hline Régime & $\begin{array}{l}\text { Témoin } \\
\text { ad lib. }\end{array}$ & $\begin{array}{l}\text { Libre choix } \\
\text { ad lib. }\end{array}$ & $\underset{\star \star}{\text { Libre choix }}$ & $\begin{array}{l}\text { Une expérimentation conduite en } \\
1991 \text { à Nouzilly (sur } 20 \text { parquets }\end{array}$ \\
\hline Consommation $(g / j / p)$ & & & & trois groupes de 100 poulets de \\
\hline Aliment total & 122 a & $136 \mathrm{~b}$ & $\$ 15 a$ & chair) suggère en effet que le \\
\hline Maîs & - & 73 & 85 & poulet s'adapte bien à la situation \\
\hline Aliment complémentaire & - & 56,5 & 24,5 & de libre choix mais que, dans nos \\
\hline Coquille & (-) & 6,5 & 5,5 & conditions, la poule pondeuse a \\
\hline EM $(\mathrm{kcal} / \mathrm{j})$ & 341 & 362 & 337 & tendance $\dot{a}$ surconsommer \\
\hline $\begin{array}{l}\text { Protéines } \\
\text { Calcium }\end{array}$ & 20 & $\begin{array}{l}30 \\
44\end{array}$ & 18 & l'aliment complémentaire s'il n'est \\
\hline valcium & 4,1 & 4,4 & 3,0 & pas rationné. $\mathrm{Ce}$ résultat est \\
\hline Performances de ponte & & & & confirmé par T. Yo en Côte d'Ivoire \\
\hline Intensité $(\%)$ & 90,2 & 88,6 & 85,4 & (1992, à paraitre) avec du maïs ou \\
\hline Poids oeuf (g) & 61,4 a & $64,7 b$ & $60,3 \mathrm{a}$ & du mil. La ration reconstituée pour \\
\hline Masse produite $(\mathrm{g} / \mathrm{j})$ & $55,4 b$ & $57,3 b$ & 51,5 a & les poulets est alors relativement \\
\hline Indice de consommation & $2,20 a$ & $2,37 b$ & $2,24 \mathrm{a}$ & lysine. \\
\hline
\end{tabular}

** Aliment complémentaire rationné distribué à $10 \mathrm{~h}$ du matin et consommé en 10 minutes.

\begin{tabular}{|c|c|c|c|c|c|c|}
\hline \multirow[b]{2}{*}{ Poulets de chair } & \multicolumn{2}{|c|}{$\begin{array}{c}\text { France } \\
100 \\
\text { poulets/traitement }\end{array}$} & \multicolumn{4}{|c|}{$\begin{array}{c}\text { Côte d'Ivoire } \\
3 \text { parquets de } 42 \text { poulets/traitement } \\
\text { Tous ad libitum. }\end{array}$} \\
\hline & $\begin{array}{l}\text { Témoin } \\
\text { ad lib. }\end{array}$ & $\begin{array}{l}\text { Libre choix } \\
\text { ad lib. }\end{array}$ & $\begin{array}{l}\text { Témoin } \\
\text { farine }\end{array}$ & $\begin{array}{l}\text { Témoin } \\
\text { granulé }\end{array}$ & $\begin{array}{l}\text { Libre choix } \\
\text { (maïs) }\end{array}$ & $\begin{array}{l}\text { Libre choix } \\
\qquad(\mathrm{mil})\end{array}$ \\
\hline ation $0-6$ semaines $(g / p)$ & 3734 & 4126 & $2823 \mathrm{c}$ & $3014 \mathrm{~b}$ & $3481 \mathrm{a}$ & $3387 a$ \\
\hline 6 semaines $(g)$ & 1858 & 1932 & $1424 c$ & $1521 \mathrm{~b}$ & $1644 \mathrm{a}$ & $1557 \mathrm{~b}$ \\
\hline consommation 0 - 6 semaines & 2,05 & 2,19 & $2,03 \mathrm{a}$ & $2,03 \mathrm{a}$ & $2,19 b$ & $2,24 b$ \\
\hline
\end{tabular}
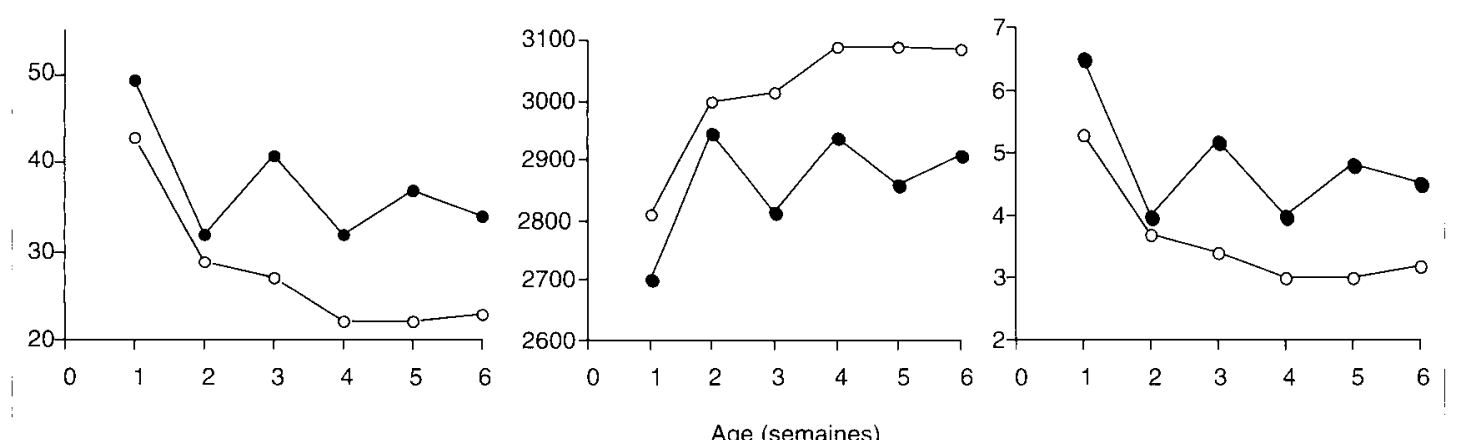

- Maïs France

- Maïs Côte d'lvoire

Age (semaines) 
alimentation en libre choix à l'entrée en ponte consomment la même quantité d'énergie mais plus de protéines que des animaux témoins recevant un régime complet unique. Leurs performances de ponte sont significativement améliorées mais la métabolisation de l'énergie ingérée et le bilan protéique sont moins bons en situation de libre choix (Scott et Balnave 1991). Ces résultats sont cohérents avec ceux présentés à l'encart 7 .

Cumming (1992) fait observer que la distribution à des poulets de chair de céréales sous forme de graines entières stimule le développement du gésier et modifie la fonctionnalité du tube digestif. Il rapproche ce fait et la plus grande résistance de ces poulets à la coccidiose. Il souligne également que, dans des conditions de stress thermique où la température diurne monte jusqu'à $33^{\circ} \mathrm{C}$, l'ingéré de graines de céréales diminue de $34 \%$ alors que l'ingéré protéique n'est réduit que de $7 \%$ par rapport à celui d'un groupe témoin maintenu à $20^{\circ} \mathrm{C}$. Les animaux placés en "libre choix" semblent en outre conserver une "mémoire" du besoin protéique et consomment le jour suivant, avant le pic thermique, les protéines qu'ils n'ont pu consommer la veille.

Si ce type d'ajustement se confirme et que nous définissons mieux comment présenter les différentes fractions de régime à l'animal, il est possible que ce type d'alimentation devienne en climat chaud une source d'amélioration des performances zootechniques. Sur le plan économique, la démarche étudiée à l'encart 7 permet de surmonter d'autres obstacles rencontrés dans certains pays chauds où le premier souci devrait être de ne pas gaspiller les matières premières importées à grand prix. Or la fabrication de mélanges approximatifs, l'oubli ou la destruction d'un micro nutriment essentiel, la contamination des aliments composés par des moisissures et leur dégradation au cours de stockages et de transports problématiques, conduisent à un gaspillage important mais mal identifié de ces matières premières. Dans les pays disposant de céréales (et peut-être même pour ceux qui les importent) ne serait-il pas dès lors plus efficace de faire fabriquer avec beaucoup de soin un aliment complémentaire unique équilibré, bien protégé et contrôlé qui serait utilisé à des taux variables en complément de céréales pour le poulet de chair, de céréales et de calcium particulaire pour la poule pondeuse ? La mise en pratique de telles solutions dépend bien entendu du niveau de technicité, des risques liés au transport et à la fabrication des régimes, et de la taille des élevages et des usines des différents pays et elles pourraient dans certains cas ne constituer que des étapes intermédiaires. Le critère essentiel doit rester le coût en devises du kilogramme d'oeuf ou de poulet produit.

Deux conclusions méritent d'être rappelées en matière d'alimentation fractionnée :

- L'alimentation calcique séparée permet d'améliorer l'ingéré énergétique et les productions des poules pondeuses en climat chaud.

- La distribution de plusieurs régimes différents (successivement ou simultanément) aux volailles ouvre des voies de recherches à approfondir.

\section{Conclusions}

L'aviculture, production animale "hors-sol" est aussi dite "aviculture de port" dans un certain nombre de pays chauds, tant sa dépendance vis à vis des importations de matières premières alimentaires payées en devises est devenue problématique. L'intégration de cette aviculture dans le développement agro-industriel global de ces pays devient donc une priorité de survie pour les filières avicoles, par ailleurs indispensables à l'approvisionnement des populations en protéines animales.

Dans cet esprit, le choix des produits et sousproduits agricoles à développer ou à valoriser, celui des normes de formulation d'un aliment pour volailles ne dépendent plus seulement de considérations climatiques et techniques mais aussi de considérations économiques à court et moyen termes. Les programmes de recherches et de développement sur la nutrition des volailles ne peuvent donc se justifier que dans une logique d'optimisation économique réaliste qui suppose de sérieux efforts de dialogue entre chercheurs, industriels et pouvoirs publics de beaucoup de pays chauds.

Dans cette optique, les ajustements qui nous semblent les plus prometteurs concernent :

- l'adaptation de la concentration énergétique des régimes aux conditions économiques en examinant en particulier les possibilités de dilution des régimes de ponte combinée à la granulation ;

- l'équilibre rigoureux des teneurs en acides aminés digestibles indispensables des régimes en évitant les excès de protéines de mauvaise qualité ;

- l'introduction de restrictions alimentaires temporaires pour éviter l'effet des pics thermiques pendant les périodes les plus chaudes;

- l'alimentation calcique séparée pour la poule pondeuse ;

- l'utilisation, dans certains contextes, d'un aliment complémentaire unique pour toutes les productions avicoles, à distribuer en complément de céréales graines entières et d'une source de calcium particulaire.

L'efficacité de ces ajustements dépendra en grande partie de l'exactitude des données utilisées dans la matrice de programmation linéaire et donc, en particulier, de l'effort consenti pour évaluer rigoureusement la valeur nutritionnelle des matières premières disponibles ou en développement.

Les possibilités limitées d'ajustement qu'offrent des régimes complets distribués ad libitum devraient stimuler la recherche de modèles alternatifs d'alimentation prenant en compte les rythmes de température et de lumière existant dans les poulaillers ouverts des pays tropicaux.

Les quelques exemples expérimentaux qui illustrent cet article soulignent l'intérêt d'une recherche menée d'une part en climat réel et d'autre part dans les conditions controlées d'une station expérimentale. Ils doivent, pour devenir utiles, être interprétés et adaptés à chaque situation locale, par les professionnels de l'aviculture. 


\section{Références bibliographiques}

Aïn Baziz H., Geraert P.A., Guillaumin S., 1990. Effects of high temperature and dietary composition on growth, body composition and energy retention in broilers. In: Proc. 8th Europ. Poult. Conf. 2528/06/1990, Barcelona (SP), vol. 1, 626-629.

Aït-Boulahsen A., Garlich J.D., Edens F.W., 1992. Relationship between blood ionized calcium and body temperature of chickens during acute heat stress. In: Proc. 19th World's Poult. Cong., 2024/09/92, Amsterdam (NL), vol. 2, 87-92.

Ait-Tahar N., Picard M., 1987. Influence des températures ambiantes élevées sur les besoins protéiques du poulet de chair en croissance. Note de Recherche. Document interne, 12 pages.

Ameur A., Picard M., 1991. Rationnement en fonction du cycle thermique et utilisation du triticale. Bilan d'un essai sur poules pondeuses. Rapport de stage du Cours Supérieur d'Aviculture, INA Paris-Grignon, Document interne, 23 pages + annexes.

Arjona A.A., Denbow D.M., Weaver W.D., 1990. Neo natally-induced thermotolerance: physiological responses. Comp. Biochem. Physiol., 95A, 393-399.

Austic R.E., 1985. Feeding poultry in hot and cold climates. In: Yousef M.K., ed. Stress physiology in livestock, vol. III Poultry, 124-136, CRC Press, Boca Raton (USA).

Barbour G., Latshaw J.D., 1992. Metabolic and economic efficiency of broiler chicks as affected by dietary protein levels. Br. Poult. Sci., 33, 569-577.

Belay T., Wiernusz C.J., Teeter R.G., 1992. Mineral balance and urinary and fecal mineral excretion profile of broilers housed in thermoneutral and heatdistressed environments. Poult. Sci., 71, 1043-1047.

Cabrera M.C., Sauveur B., Mongin P., 1982. Effect of separate calcium feeding and a limited feeding program on the metabolisable energy of the diet on nitrogen, calcium and phosphurus retention in laying hens. Reprod. Nutr. Develop., 22, 973-987.

Cowan P.J., Michie W., 1978. Environmental temperature and broiler performance: the use of diets containing increased amounts of protein. $\mathrm{Br}$. Poult. Sci., 19, 601-605.

Cumming R.B., 1992. The biological control of coccidiosis by choice feeding. In: Proc. 19th World's Poult. Cong., 20-24/09/92, Amsterdam (NL). Vol. 2, 425-428.

Daghir N.J., 1987. Nutrient requirements of laying hens under high temperature conditions. Zootech. Int., 5, 36-39.

Dale N.M., Fuller H.L., 1979. Effects of diet composition on feed intake and growth of chicks under heat stress. 1. Dietary fat levels. Poult. Sci., $58,1529-1534$.

Dale N.M., Fuller H.L., 1980. Effects of diet composition on feed intake and growth of chicks under heat stress. 2. Constant vs cycling temperatures. Poult. Sci., 59, 1434-1441.

Dongmo T., 1988. Alimentation de la poule en climat chaud. Mémoire de DEA, Université de Rennes, Sept. 88, 74 pages.
El Jack M.H., Blum J.C., 1978. The influence of high constant environmental temperature and energy levels in the diet on the performances of laying hens. Archiv. Geflügelk., 42, 216-220.

Francis C.A., Mc Leod M.G., Anderson J.E.M., 1991. Alleviation of acute heat stress by food withdrawal or darkness. Br. Poult. Sci., 32, 219-225.

Fuller H.L., Dale N.M., 1979. Effect of diet on heat stress in broilers. In: Proc. Nutr. Conf. Feed. Manufacturers. Univ. Georgia, Athens (USA), 56-59.

Geraert P.A., 1991. Métabolisme énergétique du poulet de chair en climat chaud. INRA Prod. Anim., 4(3), 257-267.

Geraert P.A., Guillaumin S., Leclercq B., 1992. Effect of high ambient temperature on growth, body composition and energy metabolism of genetically lean and fat male chickens. In: Proc. 19th World's Poult. Cong., 20-24/09/1992, Amsterdam (NL), Vol. $2,109-110$.

Hooper P., Richards S.A., 1991. Interaction of operant behaviour and autonomic thermoregulation in the domestic fowl. Br. Poult. Sci., 32, 929-938.

Hughes B.O., 1984. The principles underlying choice feeding behaviour in fowls, with special reference to production experiments. Word's Poult. Sci. J., 40, 141-150.

Hull S.J., Scott M.L., 1969. A further study on the calcium requirements of laying hens. In: Proc. Cornell Nutr. Conf. for Feed Manufacturers, 2123/10/1969, Cornell Univ., Ithaca (USA), 62-64.

Huthail N., 1992. Effects of feed withdrawal time on performance of S.C. White Leghorn layers exposed to hot weather. Poult. Sci., 71(Supp.1), 132, Abstract $n^{\circ}$ 395.

Li Y., Ito T., Nishibori M., Yamamoto S., 1992. Effects of environmental temperature on heat production associated with food intake and on abdominal temperature in laying hens. Br. Poult. Sci., 33, 113-122.

May J.D., Lott B.D., 1992a. Feed and water consumption patterns of broilers at high environmental temperatures. Poult. Sci., 71, 331-336.

May J.D., Lott B.D., 1992b. Effect of periodic feeding and photoperiod on anticipation of feed withdrawal. Poult. Sci., 71, 951-958.

McDonald M.W., 1978. Feed intake of laying hens. World Poult. Sci. J., 34, 209-221.

McNaughton J.L., Reece F.N., 1984. Response of broiler chickens to dietary energy and lysine levels in a warm environment. Poult. Sci., 63, 1170-1174.

Nir I., 1992. Optimization of poultry diets in hot climates. In: Proc. 19th World's Poult. Cong., 2024/09/1992, Amsterdam (NL), Vol. 2, 71-76.

Njoya J., 1987. Adaptation climatique de la poule pondeuse et métabolisme thyroidien. Mémoire D.E.A., Univ. Rennes (F), 82 pages.

Odom T.W., Harrisson P.C., Darre M.J., 1985. The effects of drinking carbonated water on the egg shell quality of single comb White Leghorn hens exposed to high environmental temperature. Poult. Sci., 64, 594-596. 
Olomu J.M., Offiong S.A., 1983. The performance of brown egg-type layers fed different protein and energy levels in the tropic. Poult. Sci., 62, 345-352.

Picard M., 1985. Heat effects on the laying hen Protein nutrition and food intake. In: Proc. 5th Europ. Symp. Poult. Nut., 27-31/10/1985, Maale Hachamisha (Israel), 65-72.

Picard M., Plouzeau M., 1989. Nutritional aspects of adaptation of poultry to heat stress -laying hens. In: Proc. 7th Europ. Symp. Poult. Nut., 19-21/06/1989, Lloret de Mar (SP), 83-98.

Picard M., Antoine H., Sauveur B., 1986. Influence de l'alimentation calcique séparée sur l'ingéré énergétique de la poule pondeuse soumise à un stress thermique. In: Proc. 7th Europ. Poult. Cong. 24-28/08/1986, Paris (France), Vol. 1, 406-414.

Picard M., Angulo I., Antoine H., Bouchot C., Sauveur B., 1987. Some feeding strategies for poultry in hot and humid environments. In: Proc. 10th Annual Conf. Malaysian Soc. of Anim. Prod., 24/04/1987, Genting Highlands (Malaysia), 110-116.

Ramlah H., Jalaludin S., 1989. Response of laying hens fed at specific meal times. In: Proc. 12th Annual Conf. Malaysian Soc. of Anim. Prod., 2930/03/1989, Kuala-Lumpur (Malaysia), 17-25.

Ramlah H., Sarinah A.H., 1992. Performance of layers in the tropics offered diets with and without supplemental fat. In: Proc. 19th World's Poult. Cong., 20-24/09/1992, Amsterdam (NL), Vol. 2, 107-108.

Reid B.L., Weber C.W., 1973. Dietary protein and sulfur amino-acid levels for laying hens during heat stress. Poult. Sci., 52, 1335-1343.

Rodriguez J., 1991. Alimentación de la ponedoras con dos tipos de alimentos. in Proyecto FAO CUB/8954. Documents internes.

Sauveur B., 1992. Adaptation des apports alimentaires aux variations journalières des besoins en calcium et phosphore de la poule. INRA Prod. Anim., 5(1), 19-28.

Sauveur B., Clavreul P., 1984. Favourable effect on laying performance of varying dietary levels of calcium and phosphorus during the day. In: Proc. 17th World's Poult. Cong., 8- 12/08/1984, Helsinki (Finland), 284-286.

Sauveur B., Mongin P., 1974. Effects of time-limited calcium meal upon food and calcium ingestion and egg quality. Br. Poult. Sci., 15, 305-313.

Sauveur B., Picard M., 1987. Environmental effects on egg quality. Chapter 14. In: Egg quality : current problems and recent advances. ed. by Wells R.G., Belyavin C.G., Butterworths, London (GB), 219-234.

Scott T.A., Balnave D., 1988. Comparison between concentrated complete diets and self- selection for feeding sexually maturing pullets at hot and cold temperatures. Br. Poult. Sci., 29, 613-625.

Scott T.A., Balnave D., 1989. Responses of sexuallymaturing pullets to self-selection feeding under different temperature and lighting regimens. $\mathrm{Br}$. Poult. Sci., 30, 135-150.
Scott T.A., Balnave D., 1991. Influence of temperature, dietary energy, nutrient concentration and self-selection feeding on the retention of dietary energy, protein and calcium by sexually- maturing egg laying pullets. Br. Poult. Sci., 32, 1005-1016.

Shukla R.K., Vataliya P.H., Khanna K., 1988. Influence of dietary energy-protein on production traits of caged White Leghorn layers in tropical climate. In: Proc. 18th World's Poult. Cong. 49/09/1988, Nagoya (Japan), 922-924.

Sinurat A.P., Balnave D., 1986. Free choice feeding of broilers at high temperatures. Br. Poult Sci., 27 577-584.

Smith A.J., Oliver J., 1971. Some physiological effects of high environmental temperatures on the laying hen. Poult. Sci., 50, 912-925.

Smith A.J., Oliver J., 1972. Some nutritional problems associated with egg production at high environmental temperature. Rhod. J. Agric. Res., 10, 3-60.

Smith M.O., Teeter R.G., 1987. Potassium balance of the 5-8 week old broiler exposed to constant heat or cyclic high chloride on body weight gain and feed efficiency. Poult. Sci., 66, 487-492

Sykes A.H., Salih F.I.M., 1986. Effect of changes in dietary energy intake and environmental temperature on heat tolerance in the fowl. Br. Poult. Sci., 27, 687-693.

Sykes A.H., Fataftah A.R.A., 1986a. Acclimatisation of the fowl to intermittent acute heat stress. Br. Poult. Sci., 27, 289-300.

Sykes A.H., Fataftah A.R.A., 1986b. Effect of a change in environmental temperature on heat tolerance in laying fowl. Br. Poult. Sci., 27, 307-316.

Teeter R.G., Smith M.O., Owens F.N., Arp S.C., 1985. Chronic heat stress and respiratory alkalosis occurrence and treatment in broiler chicks. Poult Sci., 64, 1060-1064.

Teeter R.G., Smith M.O., Wiernusz C.J., 1992. Research note: Broiler acclimation to heat distress and feed intake effects on body temperature in birds exposed to thermoneutral and high ambiant temperatures. Poult. Sci., 71, 1101-1104.

Uzu G., 1986. Effet de l'hygrométrie sur les performances de ponte de la poule pondeuse soumise à une température élevée. In: Proc. 7th Europ. Poult. Conf., 24-28/08/1986, Paris (F), Vol. 2, 776-784.

Uzu G., 1988. Effect of energy and separate calcium feeding on the performances of laying hens in a hot climate. In: Proc. 18th World's Poult. Cong. 49/08/1988, Nagoya (Japan), 900-902.

Uzu G., 1989. Some aspects of feeding laying hens in hot climate. In: 1st French-Egyptian Symp. Poult Sci. Develop., 28-30/03/1989, Le Caire (Egypte), M. Larbier Ed., 245-256.

Waldroup P.W., 1982. Influence of environmental temperature on protein and amino acid needs of poultry. Fed. Proc. 41 (11), 2821-2823.

Yo T., 1992. Essai d'alimentation séparée des poulets de chair en zone tropicale. IDESSA Bouake (Côte d'Ivoire). Document interne (23 pages). 


\section{Summary}

Suitable technico-economic adjustments for poultry feeding in hot countries.

Two major factors limit the development of poultry productions in countries with hot climatic conditions : the climate reduces the energy intake of birds, requires adjustments in housing systems and slows down the production rate (delayed growth, smaller eggs...) while the importation of cereals and soybean paid with major currencies handicaps many of these countries.

Suitable solutions for the nutrition of poultry must take into account these two kinds of constraints in the choice of data for formulating feed. The poultry sector must also be integrated within the general agro-industrial plans of development of the state.

Seven examples of adjustements are given here as an illustration of collaborative research between INRA and various hot countries. To become effective, such examples need to be adapted by the professionals of the poultry sector to suit local conditions.

Adjustements of feed composition using ad libitum feeding show a limited ability to compensate for the negative effects of heat on bird performance. However, some adjustments, such as increasing the amount of "poor quality" protein sources (i.e. with low essential amino acid yield) in the feed, may actually worthen the negative effects of a warm climate.

Low energy pelleted diets are suitable for the low energy consuming laying hen of the tropic. This kind of feed could use large amounts of locally available by-products which have a nutritional value for birds, such as cereal by-products.

A combined light and feed management program which prevents broilers from eating some hours before and during the daily heat peak leads to suppress the excessive mortality rate observed during the finishing period.

The splitting of a complete diet into fractions opens new perspectives. Two of these diets already have shown interesting results :

- laying hens fed on a Separate Calcium Feeding program exhibit an increase of energy intake during the morning and improved egg production,

- whole cereal grains offered in free-choice situation, together with a complementary feed (and oyster shell for layers) allows the growing or adult bird to adjust its own diet. This technic may have economic implication by using locally available grain and would limit the losses linked to storage and transportation of feed, and concentrate the technical effort on a single complementary feed.

Research for new feeding models which would include the existing rhythms of light and temperature inside open door poultry houses of tropical countries looks promising. It should stimulate scientific exchanges between Southern and Northern countries.

PICARD M., SAUVEUR B., FENARDJI F., ANGULO I., MONGIN P. 1993. Ajustements technico-économiques possibles de l'alimentation des volailles dans les pays chauds. INRA Prod. Anim., 6 (2), 87 - 103. 